\title{
In memory of Watt Wetmore Webb
}

\author{
Webb's work helped fundamentally reshape basic research and advanced manufacturing in the generation and \\ application of photonics across disciplines, from fundamental and applied physics to the biosciences.
}

W att Wetmore Webb (Fig. 1), the S. B. Eckert professor in engineering at Cornell University, passed away on 29 October 2020 , at age 93 . He entered college at age 16 and received a bachelor's degree of engineering management in 1947 from the Massachusetts Institute of Technology. This was followed by the DSc degree in materials science, physics and mathematics, also from Massachusetts Institute of Technology in 1955. Prior to his doctoral thesis, he worked at Union Carbide, which helped focus his desire to delve deeper into fundamental issues and build his motivation to go to graduate school ${ }^{1}$. He became an associate professor of engineering physics at Cornell University in 1961 and was promoted to full professor of applied physics by 1965 . He was the director of the School of Applied and Engineering Physics at Cornell University from 1983 to 1988 and was named the S. B. Eckert professor in engineering in 1988 . He became professor emeritus in 2012.

The technical excellence and breadth Webb's work was recognized by the large number of awards he received across different societies, a few of which are detailed here. He won the American Physical Society Biological (APS) Physics Prize in 1990. He was elected to the National Academy of Engineering in 1993 and the National Academy of Sciences in 1995. He received the Ernst Abbe Lecture Award of the Royal Microscopy Society in 1997. He was the recipient of the Michelson-Morley Award in 1999 and received the Rank Prize for Optoelectronics in 2000. He was named the Jablonski Award Lecturer in 2001 and received the Alexander Holland Award in Biophysics from the National Academy of Sciences in 2010. He was both an APS fellow and a fellow of the American Association for the Advancement of Science.

The multidisciplinary nature of these awards reflects the diversity of Webb's work, which resulted in over 300 articles and more than 20 patents. Several of the most prominent of these works are the development for fluorescence correlation microscopy ${ }^{2}$ and two-photon microscopy ${ }^{3}$. The impact of two-photon microscopy is summarized by the now iconic image shown in Fig. $2^{4}$. This image has been used at countless conferences by countless authors to instantly convey some of the

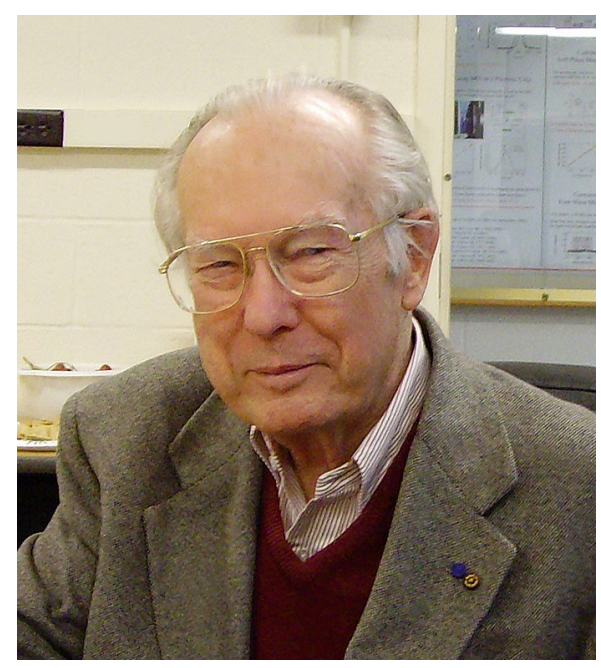

Fig. 1| Watt Wetmore Webb. Credit: Alex Kwan

most significant impacts of two-photon microscopy: one, the excitation is confined exclusively to the focal plane so that there is no out-of-focus bleaching; two, the near-infrared (NIR) wavelengths used for excitation $(700-1,100 \mathrm{~nm})$ are less damaging to biological systems; and three, unlike confocal microscopy, no detection pinhole is required. The added advantage of NIR excitation enabled deeper penetration, and as such, combined with the aforementioned benefits, quickly resulted in the adoption of this form of nonlinear imaging as the primary tool in fields such as the neurosciences.

The original two-photon microscopy work was performed using a colliding pulse mode-locked laser'. One of the broader impacts of Webb's work was that it was such a powerful tool capable of providing insight into fundamental scientific challenges it helped drive the photonics research community and the photonics industry to create more reliable, broadly tunable laser sources. Indeed, with the advent of chirped-pulse amplification ${ }^{5}$ enabling high-intensity physics and real-world applications, such as femtosecond laser-based eye surgery, coupled with the development of two-photon imaging, the stage was set - femtosecond lasers went from a novelty confined to limited research laboratories to being broadly available, produced by emergent and established

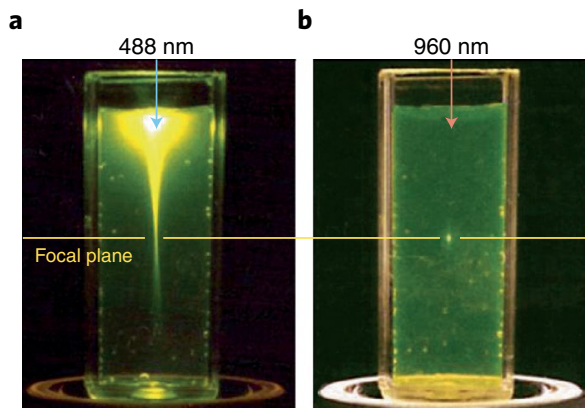

Fig. 2 | Localization of excitation by two-photon excitation. $\mathbf{a}$, Single-photon excitation of fluorophore at $488 \mathrm{~nm}$. b. Multiphoton excitation of the same fluorophore at $960 \mathrm{~nm}$. Figure reproduced with permission from ref. ${ }^{4}$, Springer Nature Ltd.

companies. Anecdotally, companies that produce femtosecond laser sources mention that the majority of their sales are for the multiphoton imaging market. This is an important part of Webb's legacy - his engineering physics intellect drove him to create new instrumentation, this new instrumentation resulted in new markets and jobs for the entire photonics community.

The Webb legacy across the decades is a role model to the community as to the value of interdisciplinary science. A small sample of his publications reveals the rich scope of his work starting with studying oxidation $(1956)^{6}$ and dislocations $(1958)^{7}$ in materials, which led into work on superconductors $(1963)^{8}$ and devices based on superconductors (1971) $)^{9}$. This was followed by the development of fluctuation correlation microscopy $(1972)^{2}$, and led into the field of biophysics $(1981)^{10}$ and the development of two-photon microscopy $(1990)^{3}$. A broad range of material and biophysical studies followed with multiphoton imaging, and the development of instruments, such as endoscopes ${ }^{11}$ that broadened the impact of these experiments.

Finally, Webb's former students and postdocs recently recognized how he provided an open-research atmosphere in his laboratory ${ }^{12}$. For those of us not fortunate enough to be able to directly work in his laboratory, Webb was also an extraordinary positive influence. We first met at an optical conference where I, as a graduate student, 
had just given a talk on how to measure femtosecond pulses at the focus of the microscope objective. I remember exiting the conference room, Webb introducing himself and asking if I would like to go for lunch with him. As a graduate student, I remember the elation at this invitation. This was the first time a professor of renown, whose work in imaging I was well acquainted with, had made such an offer. Usually, it was the other way around: I would attend talks then introduce myself, hoping to speak with established researchers and professors. Our conversation during the lunch was quite different as well. I remember how valued he made me feel. At the time,
I was repeatedly struck by how much he wanted my opinion on various aspects of multiphoton microscopy. It was a lunch that grew my self-confidence and left me with a feeling that I could also help contribute to imaging science. We will miss such an inspirational leader and great contributor to the world of science.

Jeffrey Squier (iD)

Physics Department, Colorado School of Mines, Golden, CO, USA.

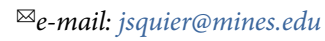

Published online: 8 June 2021

https://doi.org/10.1038/s41566-021-00833-8
References

1. Manning, A. J. Cornell Chronicle (2 November 2020); https:// news.cornell.edu/stories/2020/11/watt-webb-biologicalimaging-techniques-pioneer-dies

2. Magde, D., Elson, E. \& Webb, W. W. Phys. Rev. Lett. 29, 705-708 (1972)

3. Denk, W., Strickler, J. H. \& Webb, W. W. Science 248, 73-76 (1990).

4. Zipfel, W. R., Williams, R. M. \& Webb, W. W. Nat. Biotechnol. 21 , 1369-1377 (2003)

5. Strickland, D. \& Mourou, G. Opt. Commun. 55, 447-449 (1985)

6. Webb, W. W., Norton, J. T. \& Wagner, C. J. Electrochem. Soc. 103, 107 (1956).

7. Dragsdorf, R. D. \& Webb, W. W. J. Appl. Phys. 29, 817-819 (1958).

8. Webb, W. W. Phys. Rev. Lett. 11, 191-193 (1963).

9. Lukens, J. E., Warburton, R. J. \& Webb, W. W. J. Appl. Phys. 42, $27-30$ (1971).

10. Barak, L. S., Yocum, R. R., Nothnagel, E. A. \& Webb, W. W. Proc. Natl Acad. Sci. USA 77, 980-984 (1980).

11. Chen, M., Xu, C. \& Watt, W. W. Opt. Lett. 35, 2735-2737 (2010).

12. Zipfel, W., Xu, C., Elson, E. \& Maiti, S. J. Phys. Chem. B 125, 2793-2795 (2021) 